\title{
Análise de viabilidade econômica financeira do uso de vinhaça para geração de eletricidade no Brasil
}

\author{
GERALdo Jose FERRARESI de ARAUjo ${ }^{1}$ \\ SONIA VAlle WALTER BORges DE OLIVEIRA ${ }^{1}$
}

${ }^{1}$ Universidade de SÃo Paulo (USP) / Faculdade de Economia, Administração e Contabilidade de Ribeirão Preto, RIBEIRÃO PRETO - SP, BRASIL

\begin{abstract}
Resumo
Ante a crescente importância da geração distribuída, a pluralização da matriz energética próxima aos grandes centros de consumo tornou-se necessário. Nesse sentido, o setor de sucro energético pode contribuir para a geração de eletricidade utilizando resíduos como vinhaça, o mais relevante em volume e capacidade poluidora. Logo, objetivo geral deste artigo é analisar a viabilidade econômico do uso de vinhaça para geração de eletricidade, como objetivo específico, identificar a faixa de preço viável do MWh nos ambientes livre e regulado de energia e a capacidade produtiva das plantas para esse tipo de investimento. A metodologia utilizada foi a pesquisa quantitativa, com base na estrutura de custo de biodigestor IC, motor de combustão interna com 38\% de rendimento e logística de vinhaça em função da capacidade de produção de usina autônomas em $100 \mathrm{~m}^{3}, 1.000 \mathrm{~m}^{3}$ e $3.000 \mathrm{~m}^{3}$ etanol / dia para cenários com e sem isenção de impostos para uma faixa de preço entre US\$26,04 a US\$130,20/MWh. A análise permite observar que o uso de vinhaça para geração de eletricidade está restrito a produtores de médio e grande porte. Outrossim, o preço do MWh é mais relevante que a isenção fiscal para viabilidade deste tipo de projeto. Isso corrobora os constantes pedidos do setor sucroenergetico para realização leilões de eletricidade exclusivos para biomassa, dado sua estrutura de custos e suas as externalidades sociais, econômicas e ambientais.
\end{abstract}

Palavras-chave: Vinhaça. Eletricidade. Viabilidade econômica financeira. Mercado de eletricidade. Leilões públicos de eletricidade.

\section{Analysis of financial and economic feasibility of the use of vinasse for electricity generation in Brazil}

\begin{abstract}
In view of the growing importance of distributed generation, the pluralization of the energy matrix close to large consumption centers has become necessary. In this sense, the energy sector can contribute to electricity generation using waste products such as vinasse, the most relevant in terms of volume and polluting capacity. The general objective of this article is to analyze the economic feasibility of using vinasse for electricity generation, and as a specific objective, to identify the viable price range of MWh in free and regulated energy environments and the productive capacity of plants for this type of investment. The methodology used was quantitative research, based on the cost structure of a biodigester IC internal combustion engine with $38 \%$ yield and vinasse logistics according to the production capacity of autonomous plants of $100 \mathrm{~m}^{3}, 1,000 \mathrm{~m}^{3}$, and 3,000 $\mathrm{m}^{3}$ ethanol/day for scenarios with and without tax exemptions for a price range between US\$26.04 and US\$130.20/MWh. The analysis shows that the use of vinasse for electricity generation is restricted to medium and large producers. Furthermore, the price of MWh is more relevant than the tax exemption for the feasibility of this type of project. This corroborates the constant requests from the sugar-energy sector to hold exclusive electricity auctions for biomass, given its cost structure and its social, economic, and environmental externalities.
\end{abstract}

Keywords: Vinasse. Electricity. Financial and economic feasibility. Electricity market. Public auctions of electricity.

\section{Análisis de viabilidad económico-financiera del uso de vinaza para generación de electricidad en Brasil}

\section{Resumen}

En vista de la creciente importancia de la generación distribuida, la pluralización de la matriz energética cerca de los grandes centros de consumo se ha vuelto necesaria. En este sentido, el sector azucarero-energético puede contribuir a la generación de electricidad utilizando residuos como la vinaza, el más relevante en términos de volumen y capacidad contaminante. Por lo tanto, el objetivo general de este artículo es analizar la viabilidad económica del uso de vinaza para la generación de electricidad, como un objetivo específico, para identificar el rango de precio viable de MWh en entornos de energía libres y regulados y la capacidad productiva de las plantas para este tipo de inversión. La metodología utilizada fue la investigación cuantitativa, basada en la estructura de costos de biodigestores IC, motor de combustión interna con $38 \%$ de rendimiento y logística de vinaza de acuerdo con la capacidad de producción de la planta autónoma en $100 \mathrm{~m}^{3}, 1,000 \mathrm{~m}^{3}$ y $3,000 \mathrm{~m}^{3}$ de etanol/día para escenarios con y sin exención de impuestos para un rango de precios entre US\$26,04 a US\$130,20/MWh. El análisis muestra que el uso de vinaza para la generación de electricidad está restringido a productores medianos y grandes. Además, el precio del MWh es más relevante que la exención de impuestos para la viabilidad de este tipo de proyecto. Esto corrobora las constantes solicitudes del sector azucarero-energético para realizar subastas exclusivas de electricidad para biomasa, dada su estructura de costos y sus externalidades sociales, económicas y ambientales.

Palabras clave: Vinaza. Electricidad. Viabilidad económica y financiera. Mercado de electricidad. Subastas públicas de electricidad. 


\section{INTRODUÇÃO}

Energia elétrica é um requisito fundamental para o desenvolvimento econômico e social das nações. Dispor de fontes de energia na extensão demandada e com confiabilidade adequada às necessidades desse desenvolvimento é um fator crítico para o progresso. Além disso, essas devem ser economicamente competitivas e ambientalmente corretas.

Para Santos, Barros e Tiago Filho (2016), a eletricidade tanto no Brasil quanto no mundo tem importância fundamental para o desenvolvimento econômico e social. Há uma forte relação entre consumo de energia e desenvolvimento social. Logo, dispor de uma matriz energética diversificada, limpa, de custo baixo e estruturada é de fundamental importância para o desenvolvimento econômico e social de um país em respeito ao meio ambiente. O Brasil, embora tenha uma matriz energética plural e relativamente limpa se comparada com outras nações, possui um dos $\mathrm{kWh}$ mais caros do mundo.

De acordo com Sugimoto (2014), independente da grave situação causada pela falta de chuvas na região sudeste do país nos verões de 2013/2014 e 2014/2015, houve uma série de medidas intempestivas que trouxeram insegurança e retração nos investimentos, com incremento excessivo de termoelétrica. Com isso, os custos de produção de eletricidade se elevam e o parque industrial no Brasil perde competitividade.

A crise no setor elétrico no Brasil é uma combinação de três grandes problemas: interferência política, falta de chuvas e atrasos em investimentos. De acordo com Rodrigues (2014), o déficit no setor pode chegar a mais de US\$ 7,29 bilhões.

Para a superação dessa situação, que compromete o crescimento econômico do país e a construção do estado de bem estar social, é preciso que as políticas energéticas superem os seguintes desafios: eficiência dos sistemas existentes eliminando desperdícios e maximizando o rendimento dos processos de conversão; planejamento energético integrado; participação dos estados e da sociedade civil nas tomadas de decisão e democratização do processo de formulação e execução das políticas energéticas. Portanto, a superação dos desafios energéticos e a promoção do desenvolvimento estão interligadas, devendo ser tratadas num contexto amplo.

Em relação à transmissão de eletricidade, segundo Moreira e Millikan (2012), um quinto da energia produzida no país é desperdiçada durante sua transmissão aos centros de consumo. Em 2008, as perdas na transmissão e distribuição de eletricidade totalizaram $16 \%$ do total produzido por seu sistema de geração. A matriz energética do país, baseada em usinas hidrelétricas requer extensas linhas de transmissão. Grandes perdas implicam tarifas mais altas, que impactam o crescimento econômico. Segundo a Empresa de Pesquisas Energéticas (2014), a variação de ajustes e perdas em 2014 foi de 93.174 GWh.

Especialmente no que se refere à eficiência e ao planejamento energético, o uso mais intensivo das fontes renováveis de energia elétrica próxima aos centros de consumo, aparecem como uma das várias opções necessárias para a superação da crise em consonância com o desenvolvimento sustentável.

Para Dantas Filho e Parente (2010), a produção de energia elétrica a partir da cana de açúcar tem se mostrado de relevância ambiental, econômica e social, tendo em vista a venda de excedente para a o sistema elétrico nacional, geração de postos de trabalho, mitigação de emissão de gases efeito estufa GEE, natureza renovável, diminuição de perdas com transmissão, confiabilidade no suprimento de energia, sobretudo nos meses de estiagem e projetos de rápida implantação. A biomassa gerada pelo setor pode contribuir para o fortalecimento da matriz energética brasileira.

A produção de energia através da biomassa da cana representa uma fonte de renda importante para o setor. Dentre os vários resíduos da indústria sucroenergética: bagaço, palha, torta de filtro e vinhaça, essa última se destaca, seja pelo seu volume de produção, carga poluidora, mas também pela sua capacidade de geração de biogás quando tratada em biodigestores anaeróbios.

Nesse sentido, a vinhaça tem despertado a atenção de pesquisadores e dos principais periódicos científicos na área de energia, Moreda (2016) analisou o potencial de geração de biogás e eletricidade a partir de resíduos orgânicos no Uruguai e obteve um resultado de 2,6 milhões de $\mathrm{m}^{3} / \mathrm{ano}$, o que equivale a uma produção anual de eletricidade de 8,9 GWh/ano. Bundhoo, Mauthoor e Mohee (2016) estimaram o potencial de geração de energia a partir de vinhaça em 268 TJ/ano na ilha de Maurício e sugeriu a digestão desse resíduo como uma alternativa para reduzir a dependência pesada da ilha dos combustíveis fósseis. Segundo Moraes, Junqueira, Pavanello et al. (2014), o uso de biogás de vinhaça para geração de energia em motores estacionários de combustão interna poderia gerar 85 milhões de dólares em créditos de carbono na receita para o Brasil em 2009. 
Nogueira, Souza, Micuanski et al. (2015) estudaram a utilização desse resíduo para geração de eletricidade para a usina com capacidade de geração de $1 \mathrm{MW}$ e encontrou viabilidade econômica para todos os três cenários produtivos avaliados (primeiro: horas de produção em 7236 horas/ano; segundo: 5000 horas/ano e terceiro: de 4000 a 8000 horas/ano), somente não encontrou viabilidade no cenário 1 para o preço de US\$ 59.83 por MWh.

A contribuição do presente artigo para a literatura cientifica na área de energia esta na abordagem da utilização de vinhaça para geração de eletricidade, segundo a estrutura de custo de biodigestor IC, motor de combustão interna com $38 \%$ de rendimento e logística de vinhaça em função da capacidade de produção de usina autônomas em $100 \mathrm{~m}^{3}, 1.000 \mathrm{~m}^{3}$ e $3.000 \mathrm{~m}^{3}$ etanol / dia para cenários com e sem isenção de impostos (5,93\% sobre vendas brutas) para uma faixa de preço entre US\$26,04 a US\$130,20/MWh , base de cálculo tanto no ambiente livre quanto regulado de contratação de eletricidade no Brasil.

Com base nos artigos mencionados, este estudo tem como objetivo geral analisar a viabilidade econômico-financeira do uso de vinhaça para geração de eletricidade. O objetivo específico, por sua vez, é identificar a faixa de preço mínimo de MWh nos mercados de eletricidade livre e regulado no Brasil e a capacidade produtiva das plantas que são atrativos para esse tipo de investimento, estimulando também a discussão sobre a geração local de eletricidade, ou seja, a geração distribuída aos estados produtores de etanol.

\section{MECANISMO DE DESENVOLVIMENTO LIMPO (MDL) E BIOELETRICIDADE NO BRASIL: POLÍTICAS, IMPORTÂNCIA E DESAFIOS}

Durante a Terceira Conferência das Partes, (COP) 3, em 1997, foi anunciada a criação do Protocolo de Kyoto (PK) aonde entrou em vigor em fevereiro de 2005 e o seu primeiro período de compromisso foi entre 2008-2012. Ao final da vigência de seu período, durante a COP 18, realizada em Doha, em 2012, os países participantes comunicaram "Emenda de Doha para o Protocolo de Kyoto", deferindo um segundo período de compromisso entre 2013-2020, outrossim estabeleceram um plano para negociar um novo acordo climático pós-2020, congratulado durante a COP 21, em 2015, em Paris, conhecido como "Acordo de Paris".

O Acordo de Paris pressupõe metas para limitar as emissões de GEE, diferente do PK, países desenvolvidos e em desenvolvimento estabeleceram metas obrigatórias de redução de GEE e apoiem o desenvolvimento sustentável (art. 6, § 4, alínea a). Nesse sentido, pode se constatar que Acordo de Paris segue os objetivos do MDL, integrar a redução de emissões de GEE com a promoção do desenvolvimento sustentável (LAZARO e GREMAUD, 2017)

O MDL, criado com o PK, no art. $12^{\circ}$ e reafirmado no Acordo de Paris, em seu art. $6^{\circ}$ determina que MDL é um instrumento de duas vias, auxiliar os países industrializados a reduzir suas emissões de GEE e promover o desenvolvimento sustentável nos países em desenvolvimento, nesse sentido, os projetos de MDL no Brasil contemplaram majoritariamente setores de geração energias renováveis como hidrelétrica, eólica e biomassa com cerca de $61 \%$ dos projetos (MORI-CLEMENT e BEDNAR-FRIEDL,2019).

Para o Ministério de Minas e Energia (2017) energia é uma modalidade de investimento de longo prazo. Logo, a política e o planejamento energético devem ser capazes de traduzir escolhas relevantes para desenvolvimento sustentável. Portanto, é necessário refletir sobre uma política estratégica de estado que seja imune a mudanças governamentais e que traga segurança para investidores, empresários e consumidores. Nesse sentido, destacam-se as seguintes políticas estratégicas: Lei do Sistema Nacional de Unidades de Conservação (Lei 9.985/2000); Leilões de Energia Nova (Lei 10.848/2004); Política Nacional sobre Mudança do Clima (Lei 12.187/2009); Lei de Proteção das Florestas Nativas (Lei 12.651/2012).

Além disso, de acordo com Brasil (2020), o Fundo Nacional sobre Mudança do Clima teve um orçamento de aproximadamente $\mathrm{R} \$ 1,07$ bilhões para o período entre 2020-2023, com o objetivo de cumprir com as metas estabelecidas no Acordo de Paris para redução as emissões de GEE em 37\% abaixo dos níveis de 2005, em 2025 e, de forma indicativa, 43\% até 2030 a partir das seguintes medidas: combate ao desmatamento das florestas; aumentar a participação de biocombustíveis em $18 \%$ até 2030 e atingir 45\% de energias renováveis na matriz energética até 2030 (OLIVEIRA, GURGEL e TONRY, 2019).

Nesse sentido, a biomassa pode contribuir para a consecução das metas estipuladas no Acordo de Paris. A utilização de resíduos como bagaço, palha e vinhaça como fonte de energia, para Goldemberg e Lucon (2007), pode criar 150 vezes 
mais empregos por unidade de energia que o Petróleo. Além disso, de acordo com Bernal, Santos, Silva et al. (2017), a cana-de-açúcar é uma das fontes mais promissoras para a geração de bioenergia no contexto brasileiro, considerando que a cana-de-açúcar é colhida na estação seca, complementando a geração de eletricidade das usinas hidrelétricas, principal fonte de eletricidade no país, sendo responsável por $64 \%$ de toda a geração elétrica.

Porém, mesmo com os benefícios da bioeletricidade supracitados, entre 2014 e 2016, ante a crise no fornecimento de energia elétrica no Brasil, verificou-se a contratação de uma expressiva quantidade de termoelétricas movidas a óleo combustível para o fornecimento de energia elétrica para o Sistema Interligado Nacional. Para Lopez (2013), embora essas usinas possuam características técnicas e econômicas compatíveis para operarem na ponta do sistema e atuarem como backup, tornaram-se custosas quando passam a operar na base do sistema. Além disso, elas são intensas na emissão de GEE e os custos de operacionalização são elevados devido à natureza da matéria prima utilizada, que geralmente é importada.

De acordo Castro e Dantas (2008), exclusivo para empreendimentos de biomassa, observou-se que esse combustível vem perdendo em competitividade nos leilões, sobretudo para a energia eólica, o que vem demonstrando que os leilões estão buscando muito mais a modicidade tarifária do que a inclusão de fontes alternativas.

A pretensa falta de competitividade é o resultado da metodologia de contratação dos leilões que não auferem corretamente os benefícios da bioeletricidade para o sistema elétrico brasileiro dada a sua complementaridade no fornecimento de energia elétrica com o parque hidroelétrico nacional. A bioeletricidade sucroenergética é uma fonte de energia que contribui para a segurança da oferta brasileira de energia elétrica, mas que não tem sido devidamente valorizada nos leilões. Além disso, muitas usinas produtoras de bioeletricidade estão longe das subestações capazes de escoar a energia elétrica produzida. Com isto, o acesso à rede acaba constituindo-se em uma barreira para a incorporação de novos empreendimentos de geração movidos à bioeletricidade (CASTRO e DANTAS, 2010).

Nesse sentido, para Lopes (2013), a bioeletricidade à base de cana-de-açúcar deve se tornar competitiva em custos para obter sucesso nos leilões do Ambiente de Contratação Regulada (ACR). No entanto, no Ambiente de Contratação Livre (ACL), existem oportunidades potenciais de comércio. Os leilões no ACR apareceram para o setor sucroenergetico como uma alternativa de longo prazo que ofereceria garantias de receita de longo prazo. Essas garantias foram muitas vezes oferecidas com o objetivo de obter financiamento para a construção de projetos termoelétricos.

Por sua vez, o Ambiente de Contratação Livre se apresenta como uma opção para comercialização dos excedentes de energia elétrica, dado que as empresas compradoras e fornecedoras estabelecem acordos comerciais frequentemente mais vantajosos do que aqueles estabelecidos no Ambiente de Contratação Regulado (LOPEZ, 2013).

Para Araujo (2017), mesmo com as distorções metodológicas nos leilões a partir do Ambiente de Contratação Regulada e na contratação de termoelétricas na crise de fornecimento de energia elétrica entre 2014 e 2016, a cana-de-açúcar, principal expoente das energias renováveis, não pode se restringir à produção de etanol e queima do bagaço. Todos os seus resíduos podem ser aproveitados, tais como a palha da cana e a vinhaça para produção de energia elétrica, como também de créditos de carbono no MDL.

\section{VINHAÇA: OPORTUNIDADES E DESAFIOS}

Vinhaça um dos principais resíduos da produção de etanol, devido a sua elevada carga de material orgânico, pode ser reutilizada por meio de cogeração para produção de energia elétrica. Esse resíduo, de acordo com Hoarau (2018) um resíduo aquoso gerado pela destilação do mosto alcoólico durante o processo de produção do etanol, de caráter ácido (pH 3,5-5), com alto teor de carga orgânica, representada pela alta demanda química de oxigênio (DQO) (até $140 \mathrm{~g} / \mathrm{L}$ ), de cor marrom-escuro, devido à presença de melanoidinas e um odor desagradável. Contém nutrientes tais como azoto (até 4,2 g / I), fósforo (até 3,0 g / I) ou potássio (até 17,5 g / I).

Para Moraes, Zaiat e Bonomi (2015) vinhaça é um efluente de alto potencial poluidor, contendo altos teores de compostos orgânicos e nutrientes (principalmente potássio, mas também nitrogênio e fósforo). É derivado da etapa de destilação de etanol (deixando as colunas a uma temperatura na faixa de 85-90 graus Celsius. A presença de melanoidinas e alto teor de ácido orgânico fornece a cor acastanhada e o baixo pH. 
A vinhaça, de acordo com Christofoletti, Escher, Correia et al. (2013), também pode conter metais pesados e poluentes orgânicos xenobióticos, como fenol, cloreto de metileno, clorofórmio e pentaclorofenol, além de potássio, matéria orgânica e Nitrogenio, a vinhaça pode conter metais pesados $(\mathrm{Cu}, \mathrm{Zn}, \mathrm{Ni}, \mathrm{Mn}, \mathrm{Pb})$, mas suas concentrações são geralmente insignificantes e na maioria das vezes os metais pesados estão abaixo de seus limites de detecção no espectrofotômetro de absorção atômica (5 mg / kg para $\mathrm{Cu}, \mathrm{Zn}, \mathrm{Ni}, \mathrm{Pb}$ e $10 \mathrm{mg} / \mathrm{kg}$ para Mn). As Características Físico químicas de vinhaça em diferentes matérias primas é sintetizada na tabela 1.

Tabela 1

Características Físico químicas de vinhaça em diferentes matérias primas

\begin{tabular}{ccccc}
\hline Feedstock & Sugarcane molasses & Sugarcane juice & Corn & Beet molasses \\
\hline $\mathrm{pH}$ & $3,9-4.3$ & 4,04 & $3,3-4$ & 5,35 \\
$\mathrm{COD}(\mathrm{g} / \mathrm{L})$ & $104-134.4$ & 30.4 & $59.4-64.5$ & 91.1 \\
$\mathrm{BOD}(\mathrm{g} / \mathrm{L})$ & $46.1-96$ & 16.7 & $26.9-43.1$ & 44.9 \\
$\mathrm{~N}(\mathrm{~g} / \mathrm{L})$ & $1.66-4.2$ & 0.63 & $0.546-0.755$ & 3.57 \\
$\mathrm{~S}(\mathrm{~g} / \mathrm{L})$ & $3.24-3.42$ & 1.35 & 2.99 & 3.71 \\
$\mathrm{P}(\mathrm{g} / \mathrm{L})$ & $0.22-3.03$ & 0.13 & $0.228-1.170$ & 0,16 \\
$\mathrm{~K}(\mathrm{~g} / \mathrm{L})$ & $9.6-17.47$ & 1.95 & n.d & 10 \\
\hline
\end{tabular}

Fonte: Hoarau (2018); Wilkie, Riedesel e Owens (2000).

Koyama, Araújo Júnior, Zaiat et al. (2016), que lista as concentrações típicas de metais pesados na vinhaça a partir da cana-de-açúcar, mostrando que quando esses contaminantes estão presentes, eles estão sempre em concentrações inferiores a $0,5 \mathrm{mg} / \mathrm{l}$. A concentração dos metais pesados encontrados em vinhaça de cana de açúcar é sintetizado na tabela 2 .

Tabela 2

Metais pesados encontrados em vinhaça de cana de açúcar

\begin{tabular}{cc}
\hline Elemento & Concentração $(\mathrm{mg} / \mathrm{l})$ \\
\hline Bário & 0,41 \\
Cromo & 0,04 \\
Cobre & 0,35 \\
Mercúrio & 0,0019 \\
Molibdênio & 0,008 \\
Níquel & 0,03 \\
Zinco & 1,66 \\
\hline
\end{tabular}

Fonte: Hoarau (2018).

Considerando que o Brasil produziu na safra 2013/2014, de acordo com a União da Indústria da Cana de Açúcar (UNICA) (2014) em torno de 25,04 bilhões de litros de etanol, a produção de vinhaça nessa safra foi de no mínimo 250 bilhões de litros, sendo um volume bastante preocupante.

Os instrumentos normativos e legislações publicadas têm como objetivo, não somente mitigar o descarte da vinhaça no solo e nas coleções de águas, mas também incentivar novas aplicações para esse resíduo, com o pressuposto de promover o desenvolvimento econômico e social na sua reutilização, em consonância tanto com a preservação ambiental quanto com o Pensamento de Ciclo de Vida (PCV), de acordo com Kiss (2018), objetiva reduzir o consumo de recursos naturais, emissões de GEE e otimizar sua performance socioeconômica.

Logo, com base nas tecnologias disponíveis para reutilização da vinhaça, Oliveira (2011) enumera alternativas alinhadas tanto ao desenvolvimento sustentável quanto ao PCV, pode-se citar: biodigestão anaeróbia visando à produção de metano, fertirrigação, incineração para reutilização das cinzas na agricultura, evaporação para produção de ração animal, produção de biodiesel, produção de fungos, uso em materiais de construção e geração de eletricidade. 
No que se refere especificamente à geração de eletricidade, a mesma surge como uma alternativa na medida em que reduz o potencial poluidor e mantém as características de fertirrigação, normalizando a DQO e o pH (MORAES, JUNQUEIRA, PAVANELLO et al., 2014).

\section{METODOLOGIA}

Trata-se de uma pesquisa quantitativa, com o objetivo de analisar o valor presente liquido (VPL), taxa interna de retorno (TIR) e payback descontado do uso da vinhaça para geração de eletricidade.

Até a data de confecção do artigo não existem usinas de vinhaça, logo, estudo foi uma simulação baseada em dados secundários coletados de três órgãos: Agência Nacional do Petróleo (2017), cujos dados se referem ao tamanho das plantas produtoras de etanol; Agência Nacional de Energia Elétrica -ANEEL (2016), com dados relacionados aos preços praticados nos leilões de energia elétrica no ACR; e Câmara de Comercialização de Energia Elétrica (2017), com dados referentes aos preços praticados no ACL.

Para Araujo, Oliveira e Oliveira (2019) os cálculos foram realizados com base na utilização de um biodigestor IC e um gerador de combustão interna de rendimento de 38\%, conforme definido por Procknor (2009), para diferentes cenários de preço do MWh, respectivamente: US\$26,04, US\$ 52,08, US\$ 78,125, US\$104,16 e US\$130,20 que abarcam tanto o ACR quanto o ACL com venda de crédito de carbono a US\$18,72/t CO equivalente mitigado, de acordo com Investing (2018) e economia anual por ausência de multas em US\$ 471,35 de acordo com Simões, Sena e Campos (2004).

Segundo Poveda (2014), dada uma determinada produção de vinhaça biodigerida por dia, $5 \%$ é distribuído pelo caminhão 2318, com tanque de $15 \mathrm{~m}^{3}$; 24\% em caminhão, Volvo rodotrem, com dois tanques de $30 \mathrm{~m}^{3}$ cada, juntamente com um motor MB OM $352160 \mathrm{CV}$ e bomba EQ $9048140 \mathrm{~m}^{3}$ / h para aspersão de vinhaça e $71 \%$ transportados exclusivamente pelo motor MB OM 352160 CV e EQ 9048 Bomba de $140 \mathrm{~m}^{3} / \mathrm{h}$.

Com base nos valores de transporte da vinhaça biodigerida por dia em cada modalidade, juntamente com os valores referentes à distância média percorrida para fertirrigação, velocidade média do veículo, tempo para carregar e descarregar a vinhaça.

A Tabela 3 apresenta os valores referentes ao consumo de diesel para cada modalidade logística, número de caminhões do tipo 2318 e Volvo rodotrens necessários para o transporte da vinhaça, bem como o número de caminhoneiros, assumindo três turnos de trabalho por dia.

Tabela 3

Dados relativos às modalidades de transporte da vinhaça biodigerida

\begin{tabular}{|c|c|c|c|c|c|}
\hline $\begin{array}{l}\text { Sistema de } \\
\text { transporte e } \\
\text { aplicação }\end{array}$ & Máquina & $\begin{array}{c}\% \text { de volume de } \\
\text { vinhaça a ser } \\
\text { transportado }\end{array}$ & $\begin{array}{l}\text { Distância média } \\
\text { percorrida para } \\
\text { fertirrigação }(\mathrm{km})\end{array}$ & $\begin{array}{l}\text { Velocidade média } \\
\text { percorrida pelo } \\
\text { caminhão }(\mathrm{km} / \mathrm{h})\end{array}$ & $\begin{array}{l}\text { Tempo médio de } \\
\text { aplicação e recarga } \\
\text { de vinhaça (horas) }\end{array}$ \\
\hline $\begin{array}{l}\text { Caminhão aplicando } \\
\text { diretamente }\end{array}$ & $\begin{array}{l}\text { Caminhão } 2318 \text { com } \\
\text { tanque de } 15 \mathrm{~m}^{3}\end{array}$ & $5 \%$ & 7,00 & 35 & 0.3 \\
\hline $\begin{array}{l}\text { Caminhão } \\
\text { com aspersão } \\
\text { combinado com } \\
\text { motobomba }\end{array}$ & $\begin{array}{l}\text { Caminhão Volvo } \\
\text { rodotrem com dois } \\
\text { tanques de } 30 \mathrm{~m}^{3} \\
\text { cada e motobomba }\end{array}$ & $24 \%$ & 12,00 & 20 & 1,2 \\
\hline $\begin{array}{l}\text { Motobomba } \\
\text { em canal com } \\
\text { montagem direta } \\
\text { ou rolão }\end{array}$ & $\begin{array}{l}\text { Motor MB OM } 352 \\
160 \text { CV e Bomba } \\
\text { EQ } 9048140 \text { m³}^{3} / \mathrm{h}\end{array}$ & $71 \%$ & 63,00 & ND & ND \\
\hline
\end{tabular}

Fonte: Adaptada de Poveda (2014). 
Em relação aos custos, as despesas mensais de motoristas, encargos sobre os salários são US\$1.277,31 / motorista; consumo de combustível por safra - caminhão 2318, caminhão Volvo e motor MB OM 352 e bomba EQ 9048 (litros), custo de consumo de combustível/ safra - caminhão 2318, caminhão e trem volvo rodoviário OM OM 352 e bomba EQ 9048 (US\$) e custo da depreciação/safra da frota de caminhões 2328 e Volvo (US\$) em US\$ 1.562,50 é dado de acordo com Silva, Rios, Fraga et al. (2015) e preço do diesel em US\$ 0,87/litro de acordo com Preços de combustível (2017).

Foram considerados dois cenários: com isenção de impostos e sem isenção de impostos, ou seja, com impostos sobre a venda de energia elétrica (Programa de Integração Social (PIS), Contribuição Social sobre o Lucro Líquido (CSLL), Imposto de Renda da Pessoa Jurídica (CSLL), Imposto de Renda da Pessoa Jurídica (IRPJ) e Contribuição) para Financiamento da Seguridade Social (COFINS) a 5,93\% sobre a receita bruta, conforme definido por Nogueira, Souza, Micuanski et al. (2015).

O cenário acima mencionado foi elaborado para plantas autônomas de acordo com Moraes, Junqueira, Pavanello et al. (2014), plantas com produção exclusiva de etanol, com capacidade produtiva de $100 \mathrm{~m}^{3}$ de etanol/dia, $1.000 \mathrm{~m}^{3}$ de etanol/dia e $3.000 \mathrm{~m}^{3}$ de etanol/dia, apresentando vinhaça de COD em torno de $21 \mathrm{~kg} / \mathrm{m}^{3}, 4.800$ horas de colheita e atratividade mínima de $10 \%$ para um horizonte de 20 anos.

\section{RESULTADOS}

\section{Análise da Taxa Interna de Retorno}

Com base no resultado, o projeto é definido se a TIR for maior do que o retorno mínimo exigido. As vantagens na utilização da TIR, por estar intimamente relacionada com o VPL, corroboram para uma decisão de investimento convergente.

Logo, a TIR, para a faixa de produção de etanol considerada pode ser constatado tanto na tabela 4 quanto no gráfico 1.

\section{Tabela 4}

Taxa Interna de Retorno para venda de eletricidade a partir de vinhaça

\begin{tabular}{|c|c|c|c|c|c|c|}
\hline \multirow{2}{*}{$\begin{array}{l}\text { Preço do MWh } \\
\text { (US\$) }\end{array}$} & \multicolumn{2}{|c|}{$\begin{array}{c}\text { Produção de } 100 \mathrm{~m}^{3} \\
\text { de etanol/dia }\end{array}$} & \multicolumn{2}{|c|}{$\begin{array}{c}\text { Produção de } 1.000 \mathrm{~m}^{3} \\
\text { de etanol/dia }\end{array}$} & \multicolumn{2}{|c|}{$\begin{array}{c}\text { Produção de } 3.000 \mathrm{~m}^{3} \\
\text { de etanol/dia }\end{array}$} \\
\hline & $\begin{array}{c}\text { TIR com } \\
\text { isenção fiscal }\end{array}$ & $\begin{array}{c}\text { TIR sem } \\
\text { isenção fiscal }\end{array}$ & $\begin{array}{c}\text { TIR com } \\
\text { isenção fiscal }\end{array}$ & $\begin{array}{c}\text { TIR sem } \\
\text { isenção fiscal }\end{array}$ & $\begin{array}{c}\text { TIR com } \\
\text { isenção fiscal }\end{array}$ & $\begin{array}{c}\text { TIR sem } \\
\text { isenção fiscal }\end{array}$ \\
\hline 26,04 & ND & ND & $-8 \%$ & $-9 \%$ & $-7 \%$ & $-9 \%$ \\
\hline 52,08 & $-2 \%$ & $-3 \%$ & $7 \%$ & $6 \%$ & $7 \%$ & $6 \%$ \\
\hline 78,12 & $6 \%$ & $5 \%$ & $16 \%$ & $14 \%$ & $16 \%$ & $15 \%$ \\
\hline 104,16 & $12 \%$ & $11 \%$ & $23 \%$ & $22 \%$ & $24 \%$ & $22 \%$ \\
\hline 130,20 & $17 \%$ & $16 \%$ & $31 \%$ & $29 \%$ & $32 \%$ & $29 \%$ \\
\hline
\end{tabular}

Fonte: Elaborada pelos autores. 
Gráfico 1

Taxa Interna de Retorno para venda de eletricidade a partir de vinhaça

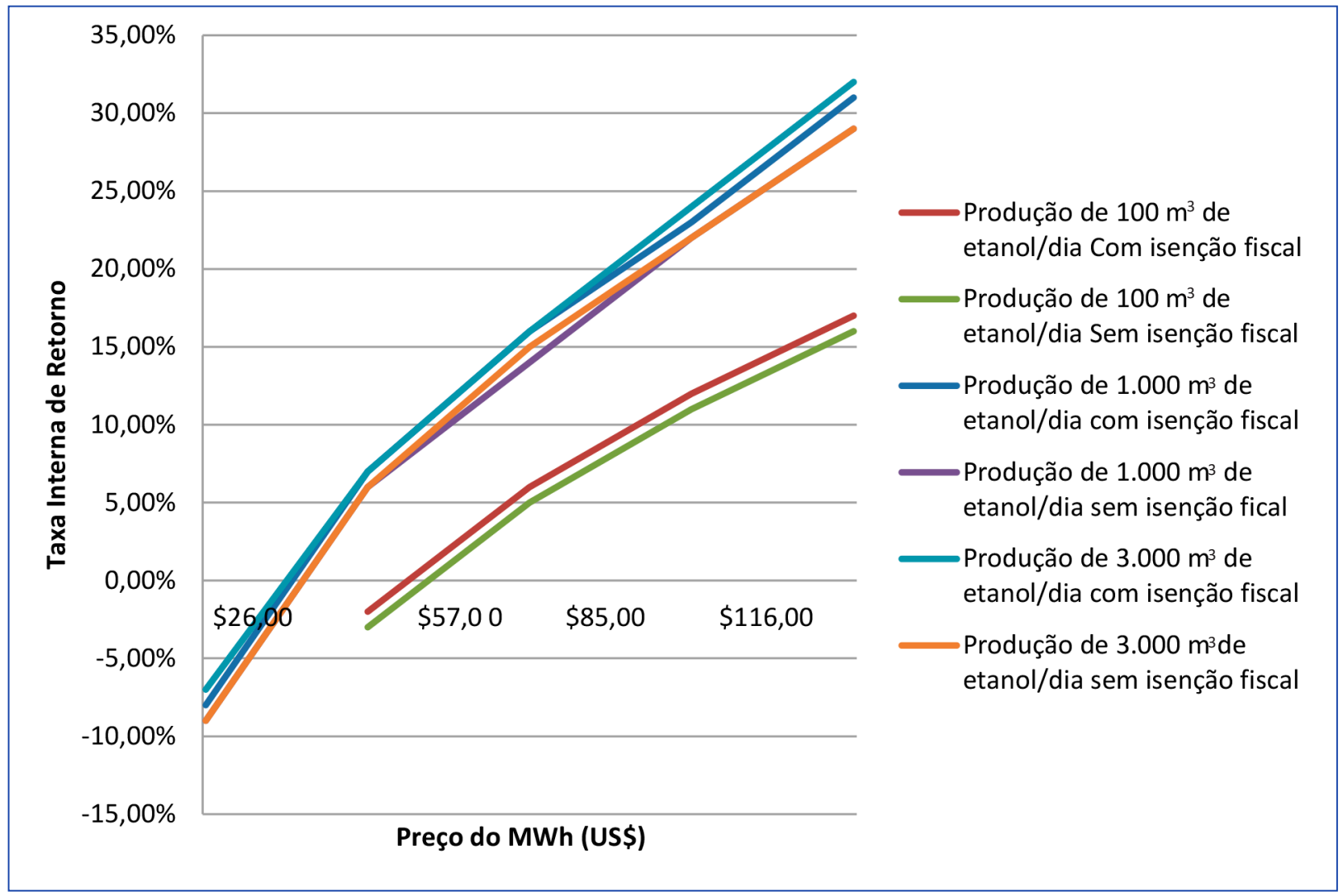

Fonte: Elaborado pelos autores.

Pode-se observar que tanto a tabela 4 quanto o gráfico 1 que quanto maior a capacidade produtiva da usina produtora de etanol, maior a atratividade econômica no que se refere à venda de eletricidade. Nesse sentido, de acordo com o método e o cenário econômico descrito, usinas com produção de $1.000 \mathrm{~m}^{3}$ e $3.000 \mathrm{~m}^{3}$ de etanol/dia, apresentam valores de TIR próximos e atrativos a investimentos, ao preço de US\$ 78,12/MWh, as destilarias com produção de $100 \mathrm{~m}^{3}$ de etanol/dia apresentam viabilidade ao preço de US\$104,16/MWh.

Além disso, quanto maior o preço do MWh, maior será a TIR do empreendimento. Para usinas com capacidade de produção de etanol em $3.000 \mathrm{~m}^{3} /$ dia, apresenta viabilidade respectivamente a partir de US\$59,98/MWh com isenção fiscal e US\$ 63,77/MWh sem isenção fiscal. Para a produção de $1.000 \mathrm{~m}^{3}$ etanol/dia, com e sem isenção fiscal, a viabilidade é de US\$ 61,00/MWh e US\$ 64,85/MWh, respectivamente. Já uma destilaria com capacidade de produção em $100 \mathrm{~m}^{3} / \mathrm{dia}$, com e sem isenção fiscal apresenta viabilidade a partir de US\$ 95,45/MWh e US\$101,47/MWh, respectivamente.

\section{Análise do Valor Presente Líquido}

A tabela 5 e a gráfico 2 apresentam o VLP para destilarias, usinas de médio e grande porte com capacidade de produção de etanol respectivamente em 100, 1.000 e $3.000 \mathrm{~m}^{3}$ etanol/ dia, para uma faixa de preço de US\$26,04 até US\$130,20 o MWh, com cenários de isenção e sem isenção fiscal, com uma carga tributária de 5,93\% sobre a receita bruta de venda de eletricidade. 
Tabela 5

Valor Presente Líquido para venda de eletricidade a partir de vinhaça

\begin{tabular}{cccccccc}
\hline & \multicolumn{2}{c}{$\begin{array}{c}\text { Produção de } 100 \mathrm{~m}^{3} \\
\text { de etanol/dia }\end{array}$} & \multicolumn{2}{c}{$\begin{array}{c}\text { Produção de } 1.000 \mathrm{~m}^{3} \\
\text { de etanol/dia }\end{array}$} & \multicolumn{2}{c}{$\begin{array}{c}\text { Produção de } 3.000 \mathrm{~m}^{3} \\
\text { de etanol/dia }\end{array}$} \\
$\begin{array}{c}\text { Preço do MWh } \\
\text { (US\$) }\end{array}$ & $\begin{array}{c}\text { VPL com } \\
\text { isenção fiscal } \\
\text { (US\$) }\end{array}$ & $\begin{array}{c}\text { VPL sem } \\
\text { isenção fiscal } \\
\text { (US\$) }\end{array}$ & $\begin{array}{c}\text { VPL com } \\
\text { isenção fiscal } \\
\text { (US\$) }\end{array}$ & $\begin{array}{c}\text { VPL sem } \\
\text { isenção fiscal } \\
\text { (US\$) }\end{array}$ & $\begin{array}{c}\text { VPL com } \\
\text { isenção fiscal } \\
\text { (US\$) }\end{array}$ & $\begin{array}{c}\text { VPL sem } \\
\text { isenção fiscal } \\
\text { (US\$) }\end{array}$ \\
\hline 26,04 & $-695.904,07$ & $-711.575,55$ & $-5.505 .378,58$ & $-5.751 .513,52$ & $-16.311 .336,08$ & $-17.062 .515,21$ \\
52,08 & $-434.810,81$ & $-465.776,47$ & $-1.404 .667,65$ & $-1.891 .011,97$ & $-3.796 .377,81$ & $-5.280 .651,86$ \\
78,125 & $-173.717,55$ & $-220.166,04$ & $2.696 .043,28$ & $1.966 .526,81$ & $8.718 .580,46$ & $6.492 .169,38$ \\
104,16 & $87.375,72$ & $25.444,39$ & $6.796 .754,21$ & $5.824 .065,58$ & $21.233 .538,72$ & $18.264 .990,62$ \\
130,20 & $348.468,98$ & $271.054,83$ & $10.897 .465,15$ & $9.681 .604,36$ & $33.748 .496,99$ & $30.037 .811,86$ \\
\hline
\end{tabular}

Fonte: Elaborada pelos autores.

Gráfico 2

Valor Presente Líquido para venda de eletricidade a partir de vinhaça

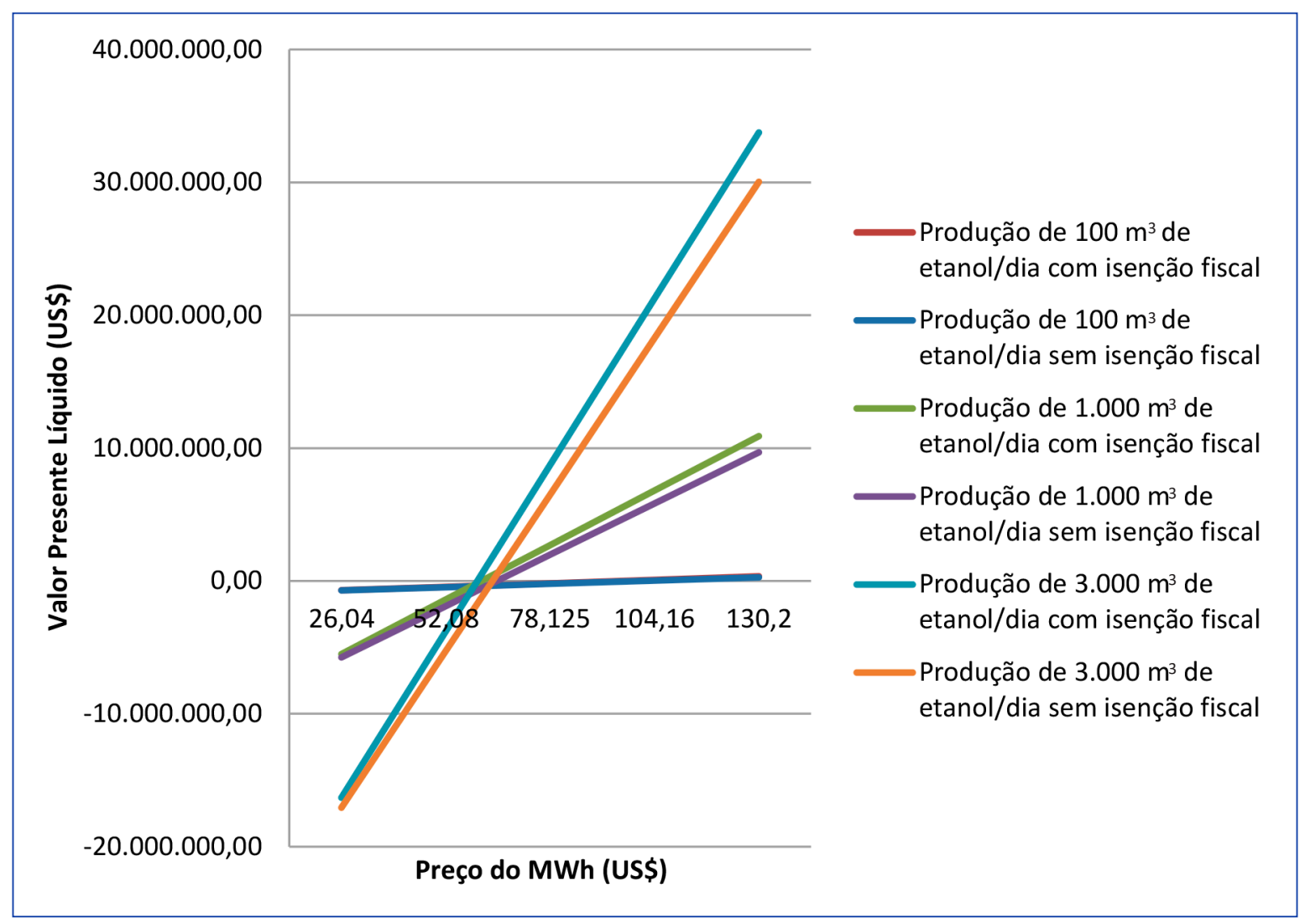

Fonte: Elaborado pelos autores.

Pode-se observar tanto na tabela 5 quanto no gráfico 2, que a capacidade produtiva da usina, no cenário econômico utilizado é determinante para a atratividade do VLP no que se refere à geração de eletricidade a partir de vinhaça. Logo, uma usina com capacidade produtiva de $3.000 \mathrm{~m}^{3}$ de etanol/dia, é mais rentável que as usinas com capacidade de produção de $1.000 \mathrm{~m}^{3}$ de etanol/dia, que por sua vez são mais atrativas que uma com produção diária de $100 \mathrm{~m}^{3}$ de etanol. 
Sendo o método do VPL mais adequado para determinar o investimento mais atrativo, pode-se afirmar, de acordo com a tabela 5 e o gráfico 2, que quanto maior a capacidade produtiva da usina maior será seu VPL. Logo, apresenta maior viabilidade a usina com capacidade produtiva de $3.000 \mathrm{~m}^{3}, 1.000 \mathrm{~m}^{3}$ e $100 \mathrm{~m}^{3}$ de etanol/dia, com e sem isenção fiscal, respectivamente.

\section{Análise do Payback descontado}

O payback descontado, para a faixa de produção de etanol considerada, para um horizonte de 20 anos, é identificado na tabela 6 e gráfico 3.

Tabela 6

Payback descontado para venda de eletricidade a partir de vinhaça

\begin{tabular}{ccccccc}
\hline & \multicolumn{2}{c}{$\begin{array}{c}\text { Produção de } 100 \mathrm{~m}^{3} \\
\text { de etanol/dia }\end{array}$} & \multicolumn{2}{c}{$\begin{array}{c}\text { Produção de } 1.000 \mathrm{~m}^{3} \\
\text { de etanol/dia }\end{array}$} & \multicolumn{2}{c}{$\begin{array}{c}\text { Produção de } 3.000 \mathrm{~m}^{3} \\
\text { de etanol/dia }\end{array}$} \\
$\begin{array}{c}\text { Preço do } \\
\text { MWh } \\
\text { (US\$) }\end{array}$ & $\begin{array}{c}\text { Payback } \\
\text { descontado } \\
\text { com isenção } \\
\text { fiscal (anos) }\end{array}$ & $\begin{array}{c}\text { Payback } \\
\text { descontado } \\
\text { sem isenção } \\
\text { fiscal (anos) }\end{array}$ & $\begin{array}{c}\text { Payback } \\
\text { descontado } \\
\text { com isenção } \\
\text { fiscal (anos) }\end{array}$ & $\begin{array}{c}\text { Payback } \\
\text { descontado } \\
\text { sem isenção } \\
\text { fiscal (anos) }\end{array}$ & $\begin{array}{c}\text { Payback } \\
\text { descontado } \\
\text { com isenção } \\
\text { fiscal (anos) }\end{array}$ & $\begin{array}{c}\text { Payback } \\
\text { descontado } \\
\text { sem isenção } \\
\text { fiscal (anos) }\end{array}$ \\
\hline 26,04 & $-583,46$ & $-403,06$ & 163,18 & 212,76 & 153,09 & 197,34 \\
52,08 & 74,15 & 87,67 & 25,79 & 29,62 & 24,82 & 28,52 \\
78,125 & 28,33 & 32,52 & 9,36 & 11,14 & 8,90 & 10,63 \\
104,16 & 14,44 & 16,78 & 2,98 & 4,11 & 2,68 & 3,79 \\
130,20 & 7,73 & 9,33 & $-0,42$ & 0,41 & $-0,64$ & 0,17 \\
\hline
\end{tabular}

Fonte: Elaborada pelos autores.

Gráfico 3

Payback descontado para venda de eletricidade a partir de vinhaça

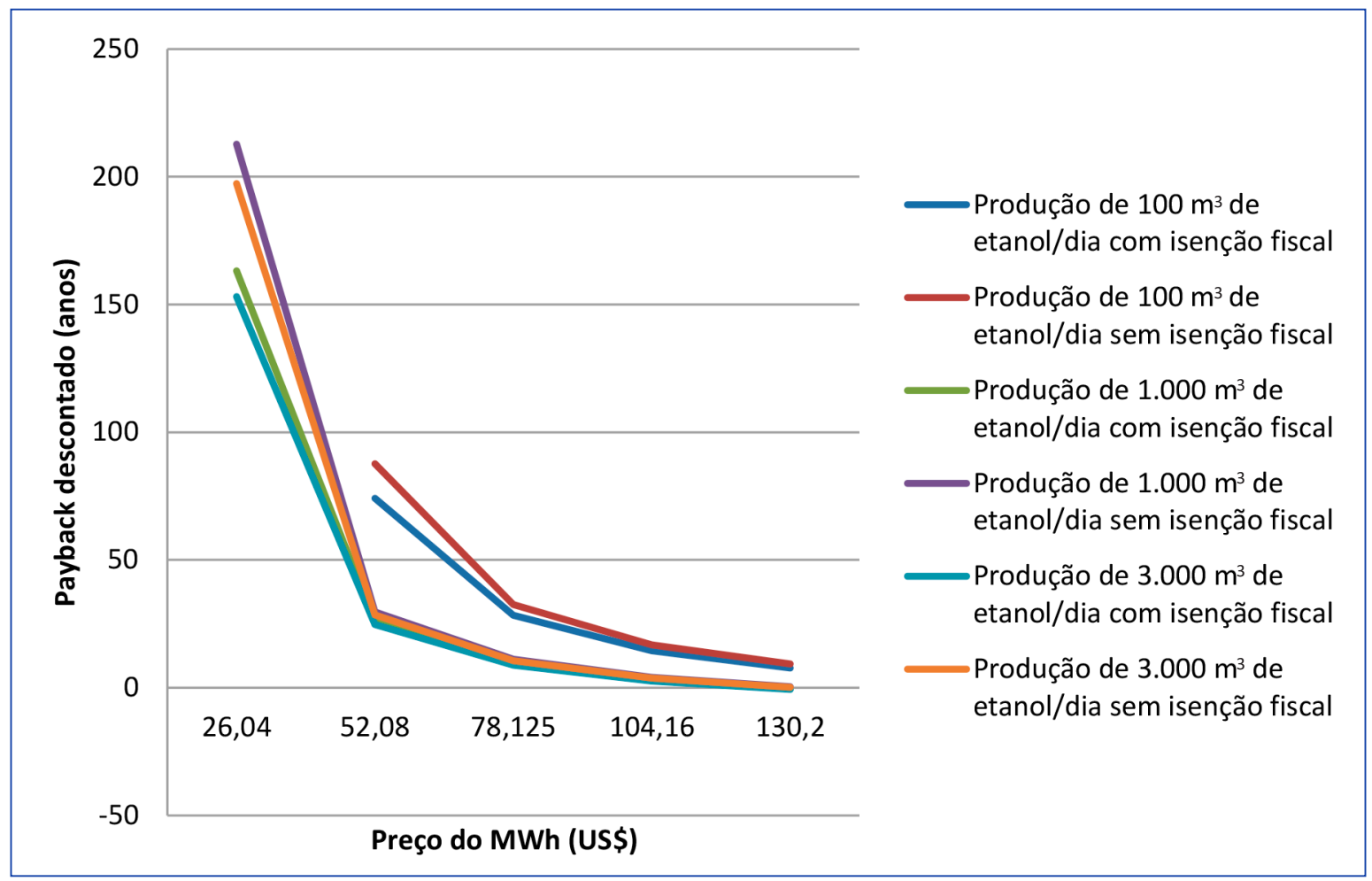

Fonte: Elaborado pelos autores. 
Como pode ser constatado tanto na tabela 6, quanto no gráfico 3, a diferença de payback descontado em função da capacidade produtiva das usinas e do preço do MWh. Logo, quanto maior a capacidade produtiva e o preço do MWh, menor será o payback descontado.

\section{DISCUSSÃO DE RESULTADOS}

Sendo a vinhaça o subproduto mais nocivo da produção de etanol, com grande volume e capacidade poluidora, faz-se necessária a discussão acadêmica sobre suas potenciais utilizações, a fim de se buscar soluções para esse grave problema ambiental. Atualmente, a vinhaça in natura é utilizada para fertilização e irrigação, com base na legislação vigente, em canaviais próximos às usinas, sejam autônomas ou anexas. Porém, o potencial energético da vinhaça está sendo desperdiçado, na medida em que sua elevada carga orgânica não está sendo utilizada seja para produção de biogás, seja para substituição do diesel ou para geração de eletricidade, por meio da biodigestão anaeróbia, objetivo desse artigo. Além disso, o processo de biodigestão anaeróbia não retira da vinhaça sua propriedade fertirrigante, o que vem ao encontro dos interesses ambientais, econômicos, energéticos e sociais do setor sucroenergético.

Especificamente no que se refere à utilização de vinhaça para geração de eletricidade, a mesma se mostra relevante tanto na complementariedade da energia hidráulica, descentralização de produção e consequente segurança no Sistema Elétrico Nacional, como defende Dantas e Parente (2010), quanto no aspecto ambiental, como na mitigação da emissão de GEE como abarca tanto a Política Nacional de Mudanças Climáticas, o Acordo de Paris, PCV e normalização dos níveis de DQO e o pH de acordo com Moraes, Junqueira, Pavanello et al. (2014).

Porém, pode-se constatar a importância do preço do MWh e da capacidade de escala para viabilidade econômica de venda de eletricidade. As usinas sucroenergéticas já estabelecidas, ante a crise no setor, adiaram ou cancelaram projetos de ampliação. Nesse sentido, o preço do MWh é a dimensão econômica que contribui decisivamente para viabilidade econômica para geração de eletricidade a partir de vinhaça.

Os resultados encontrados estão em consonância com Castro e Dantas (2008) que demonstra quantitativamente a necessidade da retomada por parte da ANEEL dos leilões exclusivos para biomassa, onde o preço do MWh seria condizente com a estrutura de custo das termoelétricas de biomassa, onde a vinhaça poderia vir a ser contemplada como um recurso para fins elétricos. Nos atuais modelos de leilões no ACR, os benefícios socioambientais da biomassa não estão sendo precificados, na medida em que os preços médios nos leilões no ACR de 2005 a 2016 ficaram, de acordo com a ANEEL (2016), em US\$ 35,87/MWh, contemplando usinas eólicas e pequenas centrais hidrelétricas, consequentemente marginalizando outros modelos, como solar e biomassa.

Sendo o preço de viabilidade do MWh para termoelétricas de vinhaça entre US\$63,77/MWh e US\$101,47/MWh, conforme demonstra a tabela 6 , nesse cenário, mesmo com capacidade produtiva em escala e políticas de isenções fiscais, as termoelétricas de vinhaça se mostram inviáveis aos atuais preços praticados nos leilões de eletricidade no ACR.

Tabela 7

Preço corte de viabilidade econômica de termoelétricas de vinhaça em função da capacidade produtiva da usina

\begin{tabular}{ccc}
\hline $\begin{array}{c}\text { Capacidade produtiva } \\
\text { da usina }\end{array}$ & $\begin{array}{c}\text { Cenário com isenção } \\
\text { fiscal }\end{array}$ & $\begin{array}{c}\text { Cenário sem } \\
\text { isenção fiscal }\end{array}$ \\
\hline $100 \mathrm{~m}^{3}$ de etanol/dia & US\$ 95,45/MWh & US\$101,47/MWh \\
$1.000 \mathrm{~m}^{3}$ de etanol/dia & US\$61,00/MWh & US\$64,85/MWh \\
$3.000 \mathrm{~m}^{3}$ de etanol/dia & US\$59,98/MWh & US\$63,77/MWh \\
\hline
\end{tabular}

Fonte: Elaborada pelos autores. 
Preço corte de viabilidade econômica de termoelétricas de vinhaça em função da capacidade produtiva da usina

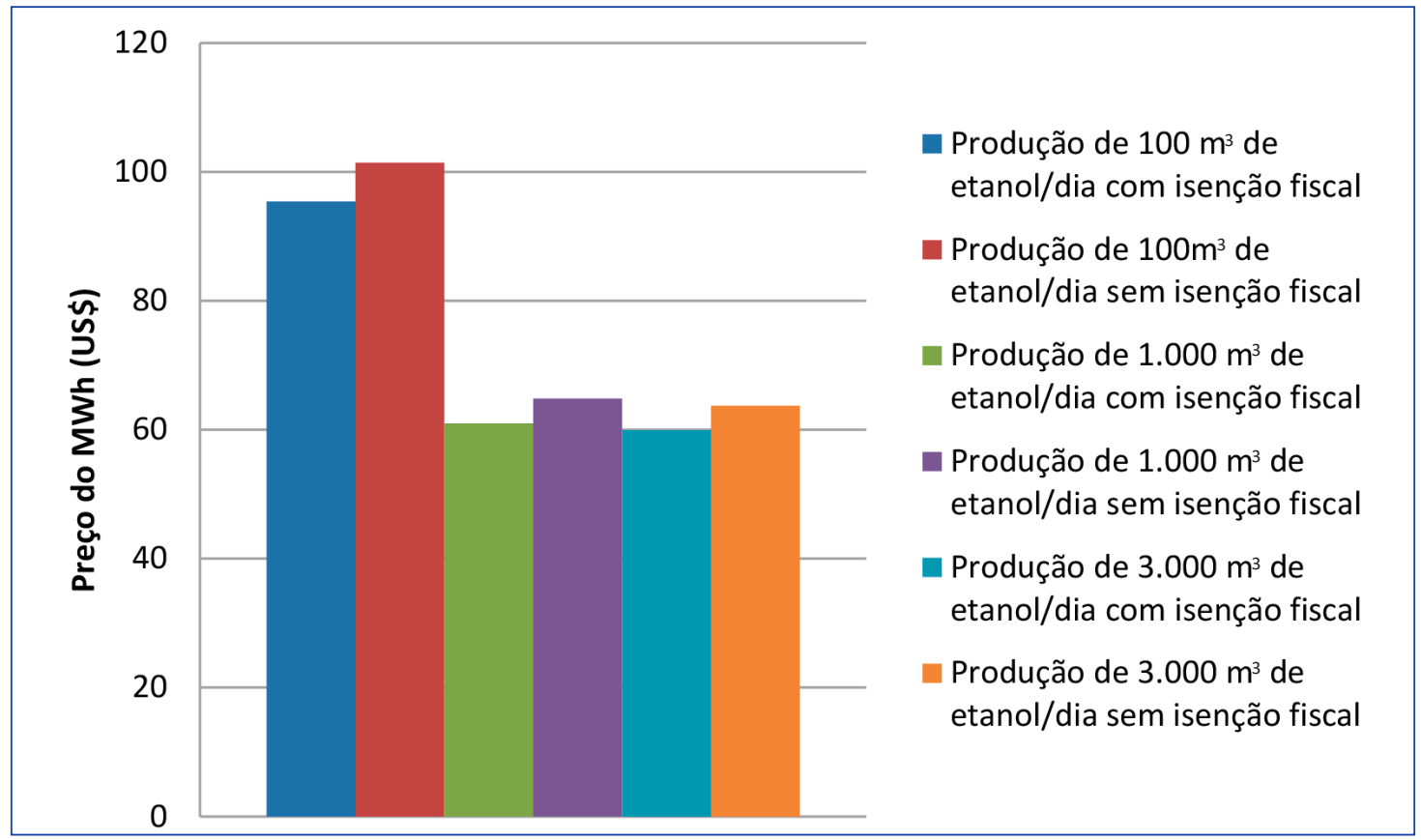

Fonte: Elaborado pelos autores.

A retomada de leilões exclusivos para biomassa no ACR tem também importância para dar sustentabilidade econômica para o empreendedor a longo prazo, através de um fluxo de caixa que permita que o investimento se pague, remunerando o empreendedor e as instituições financeiras. No ACL, embora o preço do MWh seja mais atrativo, o mesmo apresenta tanto maior volatilidade quanto períodos de contratos mais curtos, se comparado com o ACR; nesse sentido, apresenta riscos de variação de preços e contratos que não sejam suficientemente logos para quitação do empreendimento.

Consequentemente, não sendo um parâmetro adequado para realização de análise de viabilidade, o que consequentemente reforça a importância dos leilões no ACR para o fomento de novos empreendimentos elétricos em consonância com o desenvolvimento sustentável. 


\section{CONCLUSÃO E IMPLICAÇÕES POLÍTICAS}

A eletricidade tem importância estratégica para o desenvolvimento das nações. Logo, dispor de um parque elétrico que sustente o crescimento econômico, o bem-estar social, em consonância com a preservação ambiental e próxima dos centros consumidores é de fundamental importância como vantagem competitiva de nações.

A geração de eletricidade próxima dos centros consumidores e em consonância com o tripé da sustentabilidade encontra-se o setor sucroenergético. Este setor, além da produção de etanol e açúcar, contribui substancialmente na produção de eletricidade limpa, renovável e distribuída no espaço geográfico. Ante a crise de custo no setor elétrico nacional, a reutilização de seus resíduos para geração de eletricidade pode contribuir de maneira a não só atenuar as crises supracitadas, como também mitigar tanto a emissão de GEE, como também as perdas em transmissão e distribuição.

Em suma, a geração de energia elétrica através da vinhaça pode contribuir para a diminuição dos impactos ambientais causados por esse resíduo, aumento da produção de energia elétrica em âmbito local, diminuição das perdas de energia elétrica no processo de transmissão, ampliação ou criação de novo mercado com a comercialização da bioeletricidade através dos leilões de energia elétrica pela ANEEL, potencial substituição da palha e do bagaço para geração de eletricidade, com consequente incremento na produção de etanol de segunda geração a partir da disponibilidade dos mesmos.

\section{AGRADECIMENTOS}

Os autores agradecem ao Conselho Nacional de Desenvolvimento Científico e Tecnológico (CNPq) pelo estimulo a pesquisa processo no. 134.193 / 20.156. 


\section{REFERÊNCIAS}

AGENCIA NACIONAL DE ENERGIA ELETRICA. Resumo do resultado dos leilões de geração no ACR de 2005 a 2016. Brasília: ANEEL, 2016.

AGENCIA NACIONAL DE PETROLEO. Dados estatísticos. Brasília, 2017.

ARAUJO, G. J. F. Análise energética, ambiental, e econômica de biodigestores de circulação interna e concentradores de vinhaça para geração de eletricidade, fertilizantes e créditos de carbono em diferentes cenários econômicos. 2017. Dissertação (Mestrado em Administração de Organizações) - Faculdade de Economia, Administração e Contabilidade de Ribeirão Preto, Universidade de São Paulo, Ribeirão Preto, 2017.

ARAUJO, G. J. F. et. al. Economic Analysis of Internal Circulation Biodigesters and Vinasse Concentrators for the Generation of Electricity, Fertilizers, and Carbon Credits in Various Brazilian Economic Scenarios. Bioenergy Research, v. 12, p. 1164-1186, 2019.

BERMANN, C. et al. O setor elétrico brasileiro e a sustentabilidade no século XXI - oportunidades e desafios. 2. ed. Brasilia: International rivers network. 2012.

BERNAL, A. P. et al. Vinasse biogas for energy generation in Brazil: An assessment of economic feasibility, energy potential and avoided $\mathrm{CO} 2$ emissions. Journal of cleaner production, v. 151, p. 260-271, 2017.

BRASIL. Lei no 12.187, de 29 de dezembro de 2009. Institui a Política Nacional sobre Mudança do Clima - PNMC e dá outras providências. Diário Oficial da União, Brasília, DF, 30 dez. 2009.

BRASIL. Lei no 13.971, de 27 de dezembro de 2019. Institui o Plano Plurianual da União para o período de2020 a 2023. Diário Oficial da União, Brasília, DF, 30 dez. 2019.

BUNDHOO, Z. M. A.; MAUTHOOR, S.; MOHEE, R. Potential of biogas production from biomass and waste materials in the Small Island Developing State of Mauritius. Renewable and Sustainable Energy reviews, v. 56, p. 1087-1100, 2016.

CAMARA DE COMERCIALIZAÇÃO DE ENERGIA ELETRICA. Histórico de preços semanais. São Paulo, 2017.

CASTRO, N. J.; DANTAS, G. A. A Conexão da Bioeletricidade à Rede: Quem Paga?. Rio de Janeiro, 2008.

CHRISTOFOLETTI, C. A. et al. Sugarcane vinasse: environmental implications of its use. Waste management, v. 33, n. 12, p. 2752-2761, 2013.

DANTAS FILHO, P. L. Análise de custos na geração de energia com bagaço de cana-de-açúcar: um estudo de caso em quatro usinas em São Paulo. 2009. Dissertação (Mestrado em Energia) - Energia, Universidade de São Paulo, São Paulo, 2009.

EMPRESA DE PESQUISAS ENERGETICAS. Relatório Final de 2014. Rio de Janeiro, 2014.

GOLDEMBERG, J.; LUCON, O. Energias renováveis: um futuro sustentável. Revista USP, São Paulo, n. 72, p. 6-15, 2007.

HOARAU, J. et al. Sugarcane vinasse processing: Toward a status shift from waste to valuable resource. A review. Journal of water process engineering, v. 24, p. 11-25, 2018.

INVESTING. Preço do crédito de carbono no mercado futuro. São Paulo, 2017.
KISS, B. C. K. Análise da aplicação do pensamento de ciclo de vida na gestão empresarial: estudo de casos brasileiros. 2018. Dissertação (Mestrado Profissional em Administração) - Escola de Administração de Empresas de São Paulo, Fundação Getúlio Vargas, São Paulo, 2018.

KOYAMA, M. H. et al. Kinetics of thermophilic acidogenesis of typical Brazilian sugarcane vinasse. Energy, v. 116, p. 1097-1103, 2016.

LAZARO, L. L. B.; GREMAUD, A. P. Contribuição para o desenvolvimento sustentável dos projetos de mecanismo de desenvolvimento limpo na América Latina. Organizações e Sociedade, v. 24, n. 80, p. 53-72, 2017.

LOPES, O. A. Avaliação de métodos avançados de geração de energia elétrica na indústria de açúcar e bioenergia. 2013. Dissertação (Mestrado em Economia)-Escola de Economia de São Paulo, Fundação Getúlio Vargas, São Paulo, 2013.

MINISTERIO DE MINAS E ENERGIA. Plano de expansão de energia de 10 anos. Brasília, 2017.

MORAES, B. et al. Anaerobic digestion of vinasse from sugarcane biorefineries in Brazil from energy, environmental, and economic perspectives: Profit or expense? Aplied Energy, v. 113, p. 825-835, 2014.

MORAES, B. S.; ZAIAT, M.; BONOMI, A. Anaerobic digestion of vinasse from sugarcane ethanol production in Brazil: challenges and perspectives. Renewable and Sustainable energy reviews, v. 44, p. 888-903, 2015.

MOREDA, I. L. The potential of biogas production in Uruguay. Renewable and Sustainable Energy Reviews, v. 54, p. 1580-1591, 2016

MORI-CLEMENT, Y.; BEDNAR-FRIEDL, B. Do clean development mechanism projects generate local employment? Testing for sectoral effects across Brazilian municipalities. Ecological economics, v. 157, p. 47-60, 2019.

NOGUEIRA, C. E. C. et al. Exploring possibilities of energy insertion from vinasse biogas in the energy matrix of Paraná State, Brazil. Renewable and Sustainable Energy Reviews, v. 48, p. 300-305, 2015

OLIVEIRA, M. Vinhaça alternativa: resíduo da produção de etanol pode ser usado para produzir biodiesel. Pesquisa FAPESP, São Paulo, n. 186, p. 70-73, ago. 2011.

OLIVEIRA, T. D.; GURGEL, A. C.; TONRY, S. International market mechanisms under the Paris Agreement: A cooperation between Brazil and Europe. Energy policy, v. 129, p. 397-409, 2019.

POVEDA, Manuel Moreno Ruiz. Análise econômica e ambiental do processamento da vinhaça com aproveitamento energético. 2015. Dissertação (Mestrado em Energia) - Instituto de Energia e Ambiente, Universidade de São Paulo, São Paulo, 2015.

PREÇO DE COMBUSTÉVEIS. Preço do diesel em Ribeirão Preto. Ribeirão Preto, 2017

PROCKNOR, C. Energia elétrica a partir vinhaça. UNICA, 2009.

RODRIGUES, E. Para conter rombo do setor elétrico, governo reduz preço máximo da energia. Estadão, São Paulo. 2014.

SANTOS, I. F. S. et al. Electricity generation from biogas of anaerobic wastewater treatment plants in Brazil: an assessment of feasibility and potential. Journal of cleaner production, v. 126, p. 504-514, 2016. 
SILVA, T.A. et al. Estudo da viabilidade de implantação de um concentrador de vinhaça em uma usina produtora de etanol. In: ENCONTRO NACIONAL DE ENGENHARIA DE PRODUÇÃO, 35; Fortaleza, 2015. Anais... Fortaleza. ENEGEP, 2015. Artigos, p. 1-15.

SIMOES, C. L. N., SENA, M. E. R., CAMPOS, R. Estudo da viabilidade econômica da concentração de vinhoto através de osmose inversa. In: ENCONTRO NACIONAL DE ENGENHARIA DE PRODUÇÃO, 24, Florianópolis, 2004. Anais... Florianópolis: ENEGEP, 2004. Artigos, p. 1-8.
SUGIMOTO, L. Crise no setor energético: como entramos e como sair. Campinas, 2014.

UNIÃO DAS INDUSTRIAS DA CANA DE AÇUCAR. Revisão de estimativa da safra 2013/2014 no centro sul confirma crescimento de moagem direcionado para a produção de etanol. São Paulo, 2014.

WILKIE, A. C. et al. Stillage characterization and anaerobic treatment of ethanol stillage from conventional and cellulosic feedstocks. Biomass and Bioenergy, v. 19, n. 2, p. 63-102, 2000.

Geraldo Jose Ferraresi de Araujo

Bacharel e Mestre em Administração pela Faculdade de Economia, Administração e Contabilidade de Ribeirão Preto da Universidade de São Paulo (USP), Ribeirão Preto - SP, Brasil. E-mail: geraldoferraresi@usp.br 


\section{APÊNDICE}

Tabela A1

Dados de safra e insumos agroindustriais

\begin{tabular}{lc}
\hline Dias de safra & 200,00 \\
Período de safra (meses) & 7,00 \\
Horas de funcionamento do concentrador/ horas de safra & $4.800,00$ \\
Produção de etanol/dia $\left(\mathrm{m}^{3}\right)$ & Dado \\
Produção de vinhaça/dia $\left(\mathrm{m}^{3}\right)$ & $\mathrm{A} 1$ \\
Produção de etanol/ano $\left(\mathrm{m}^{3}\right)$ & $\mathrm{A} 2$ \\
Produção de vinhaça/ano $\left(\mathrm{m}^{3}\right)$ & $\mathrm{A} 3$ \\
DQO de vinhaça $\left(\mathrm{Kg} / \mathrm{m}^{3}\right)$ & 21,00 \\
\hline
\end{tabular}

Fonte: Elaborada pelos autores.

\section{Biodigestor}

Tabela A2

Valor de investimento no biodigestor e motogerador

\begin{tabular}{lccc} 
& Preço Unitário & Unidade & Preço total \\
\hline Biodigestor IC e dessulfuridificador & US\$ 22,13/(KgDQO/dia) & A4 & A5 \\
Motogerador & US\$ 442,70/Kw & A6 & A7 \\
\hline \multicolumn{2}{c}{ Total de investimento } & & A8 \\
\hline
\end{tabular}

Fonte: Elaborada pelos autores.

Tabela A3

Valor de operação e manutenção anual de biodigetor e motogerador

\begin{tabular}{lccc} 
& Preço unitário & Unidade & Preço total \\
\hline Biodigestor e dessuluridificador & US\$0,0041/Kg DQO & A9 & A10 \\
Motogerador & US\$ 10,41/MWh & A11 & A12 \\
\hline \multicolumn{2}{c}{ Total anual de operação e manutenção } & & A13
\end{tabular}

Fonte: Elaborada pelos autores.

Tabela A4

Dados com logística de vinhaça in natura

\begin{tabular}{lc}
\hline \multicolumn{1}{c}{ Evento } & Custo \\
\hline $\begin{array}{l}\text { Custo mensal de motorista mais encargos trabalhistas e sociais sobre } \\
\text { o salario (US\$) }\end{array}$ & US\$ 1.277,31 \\
Preço do diesel pago pela usina US\$/litro & US\$ 0,87 \\
$\begin{array}{l}\text { Depreciação e O\&M mensal por caminhão } 2318 \text { e caminhão Volvo } \\
\text { rodotrem (US\$) }\end{array}$ & US\$ 1.562,50
\end{tabular}

Fonte: Elaborada pelos autores. 


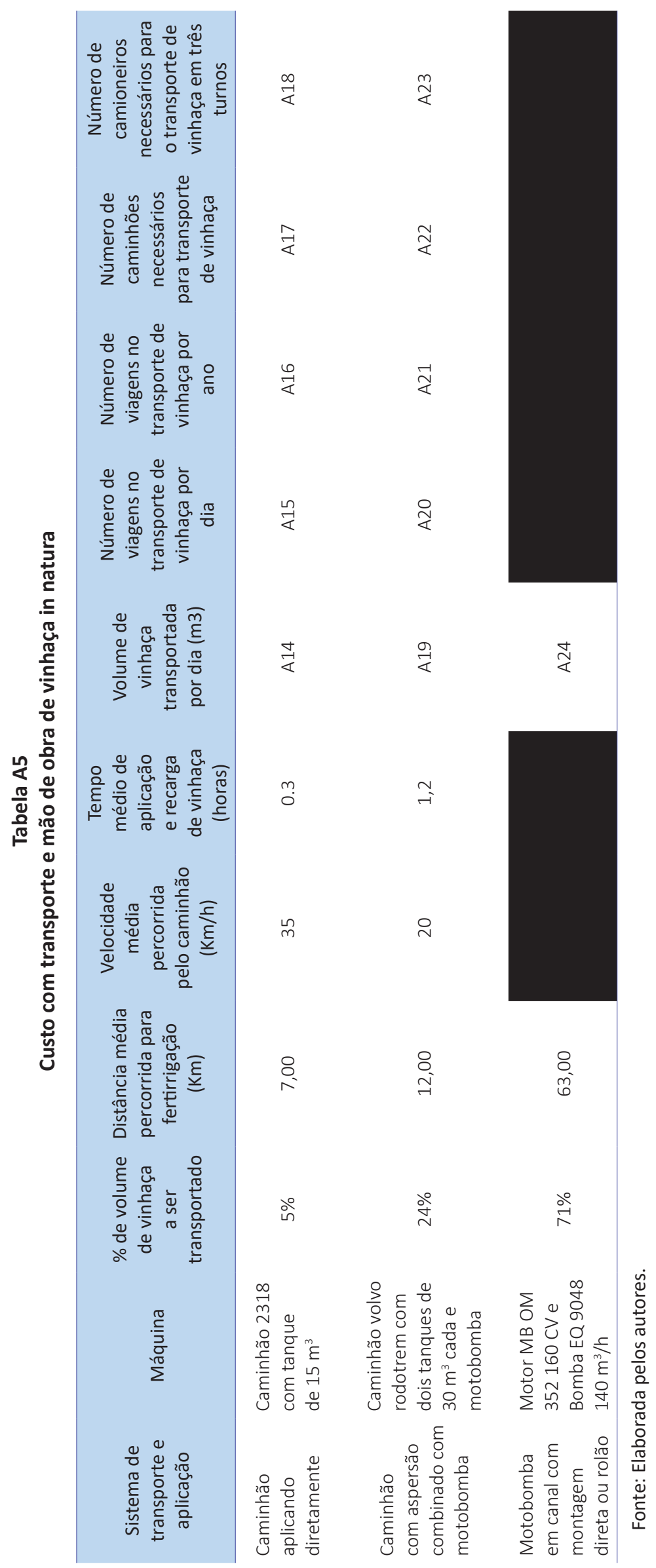


Tabela A6

Custos com Logística de vinhaça in natura

\begin{tabular}{|c|c|}
\hline Custo mensal de motorista mais encargos trabalhistas e sociais sobre o salario (US\$) & A25 \\
\hline $\begin{array}{l}\text { Consumo de combustível por safra- caminhão 2318, caminhão Volvo rodotrem e motor MB OM } \\
352 \text { e bomba EQ } 9048 \text { (litros) }\end{array}$ & A26 \\
\hline $\begin{array}{l}\text { Custo de consumo de combustível por safra- caminhão 2318, caminhão volvo e motor MB OM } 352 \\
\text { e bomba EQ } 9048 \text { (US\$) }\end{array}$ & A27 \\
\hline Custo de depreciação por safra da frota de caminhões 2328 e Volvo rodotrem (US\$) & A28 \\
\hline
\end{tabular}

Fonte: Elaborada pelos autores.

Tabela A7

Economia por ausência de multa

Economia por ausência de multa US\$ 471,35

Fonte: Elaborada pelos autores.

\section{Biodigestor IC}

Tabela A 8

Resumo dos dados financeiros

\begin{tabular}{ll}
\hline Vida útil (anos) & 20 \\
Preço do MWh & US\$ 26,04, US\$ 52,08, US\$ 78,125, US\$ 104,16 e US\$130,20 \\
Preço da tCO 2 eq & US\$18,72 \\
Taxa de desconto & $10,00 \%$ \\
\hline
\end{tabular}

Fonte: Elaborada pelos autores.

Tabela A9

Fluxo de caixa

\begin{tabular}{|c|c|c|c|c|c|}
\hline Receita & Unidade & Quantidade & ano 1 & ano 2 & (...) ano 20 \\
\hline Venda de eletricidade (ACR) & MWh/ano & $\mathrm{A} 30$ & A31 & A31 & A31 \\
\hline Venda de crédito de carbono (MDL) & $\mathrm{tCO}_{2} \mathrm{eq} / \mathrm{ano}$ & A32 & A33 & A33 & A33 \\
\hline \multirow[t]{2}{*}{ Economia por ausência de multa } & 1/ano & US\$ 471,35 & US\$ 471,35 & US\$ 471,35 & US\$ 471,35 \\
\hline & & Receita total & A34 & A34 & A34 \\
\hline Despesa & Unidade & Quantidade & ano 1 & ano 2 & (...) ano 20 \\
\hline O\&M do biodigestor e dessulfuridificador & US\$/Kg DQO & A9 & A10 & A10 & A10 \\
\hline O\&M do motogerador & US\$/MWh & A11 & A12 & A12 & A12 \\
\hline \multirow[t]{3}{*}{$\begin{array}{l}\text { Impostos sobre venda (6\%), renda ( } 25 \%) \\
\text { e contribuições sociais }(9 \%) \text { sobre a } \\
\text { venda de eletricidade }\end{array}$} & US\$ & $5,95 \%$ & A35 & A35 & A35 \\
\hline & & Total de despesa & A36 & A36 & A36 \\
\hline & & Fluxo Líquido & A37 & A37 & A37 \\
\hline
\end{tabular}

Fonte: Elaborada pelos autores. 


\section{EQUAÇÕES}

Eq A1: Produção de etanol/dia $\left(\mathrm{m}^{3}\right) \times 10$

Eq A2: Produção de etanol/dia $\left(\mathrm{m}^{3}\right) \times$ dias de safra (200 dias)

Eq A3: Eq A2 x 10

Eq A4: Eq A1 x 21 (DQO de vinhaça em usinas autônomas $\left(\mathrm{Kg} / \mathrm{m}^{3}\right)$

Eq A5: Eq A4 x US\$22,13 (Preço do KgDQO/dia)

Eq A6: (Eq A2 x 6 (Volume de biogás produzido por $\mathrm{m}^{3}$ de vinhaça $\left.\left(\mathrm{N} \mathrm{m}^{3} / \mathrm{m}^{3}\right)\right) \times(1-0,05) \times 17.765,00$ (Poder calorífico inferior do biogás) / 1.000.000.000) x 0,38 (Rendimento termoelétrico do motor)/ 4.800 (Horas de safra no ano) x 1000

Eq A7: Eq A6 x US\$ 442,70 (Preço do Kw)

Eq A8: Eq A5 + Eq A7

Eq A9: Eq A3 x 21 (DQO de vinhaça em usinas autônomas $\left(\mathrm{Kg} / \mathrm{m}^{3}\right.$ )

Eq A10: Eq A9 x US\$ 0,0041 (Preço do Kg DQO)

Eq A11: (Eq A6/1000) x 4.800 (Horas de funcionamento por safra)

Eq A12: Eq A11 x US\$ 10,41 (Preço do MWh)

Eq A13: Eq A10 + Eq A12

Eq A14: Eq A1 x 5\% (\% de Volume de vinhaça a ser transportado pelo caminhão 2318)

Eq A15: Eq A14 / 15 (Volume em m³ transportado pelo caminhão 2318)

Eq A16: Eq A15 x 200 (Dias de safra no ano)

Eq A17: Eq A14 / 360 (Volume máximo em $\mathrm{m}^{3}$ de vinhaça transportado por um caminhão 2318 transportado em um dia de trabalho em três turnos)

Eq A18: Eq A17 x 3 (turnos de trabalho)

Eq A19: Eq A1 x 24\% (\% de Volume de vinhaça a ser transportado pelo caminhão Volvo rodotren)

Eq A20: Eq A10 / 60 (Volume em $\mathrm{m}^{3}$ transportado pelo caminhão Volvo rodotren)

Eq A21: Eq A20 x 200 (Dias de safra no ano)

Eq A22: Eq A19 / 600 (volume máximo em $\mathrm{m}^{3}$ de vinhaça transportado por um caminhão volvo rodotren transportado em um dia de trabalho em três turnos)

Eq A23: Eq A22 x 3 (turnos de trabalho)

Eq A24: Eq A1 x 71\% (\% de Volume de vinhaça a ser transportado pelo motor MB OM 352160 CV e bomba EQ 9048)

Eq A25: US\$ 1.277,31 (Custo mensal de motorista mais encargos trabalhistas e sociais sobre o salario) x (Eq A18 + Eq A23) $x$ 7 (Período de safra em meses)

Eq A26: (Eq A24/7,5 (Volume de vinhaça bombeada em m³ por consumo de um litro de diesel de Motor MB OM 352160 CV e Bomba EQ $\left.9048\left(\mathrm{~m}^{3}\right)\right)+($ Eq A15 x 6,36 (Volume de diesel consumido pelo caminhão 2318 em uma viagem no transporte de vinhaça concentrada (litros/viagem)) + (Eq A20 x 18,46 (Volume de diesel consumido pelo caminhão Volvo rodotrem em uma viagem no transporte de vinhaça concentrada (Litros/viagen))) + (Eq A19/7,5 (Volume de vinhaça bombeada em $\mathrm{m}^{3}$ por consumo de um litro de diesel de Motor MB OM 352160 CV e Bomba EQ $\left.9048\left(m^{3}\right)\right)$ x (200 (Dias de safra)))

Eq A27: Eq A26 x US\$ 0,87 (Preço do diesel pago pela usina US\$/litro)

Eq A28: (US\$ 1.562,50 (Depreciação e O\&M mensal por caminhão 2318 e caminhão Volvo rodotrem) x (Eq A17 + Eq A22)) x 7 (Período de safra em meses) 
Eq A29: Eq A25 + Eq A26 + Eq A27 + Eq A28

Eq A30: (Eq A2 6 (Volume de biogás produzido por $\mathrm{m}^{3}$ de vinhaça $\left.\left(\mathrm{N} \mathrm{m}^{3} / \mathrm{m}^{3}\right)\right) \times(1-0,05) \times 17.765,00$ (Poder calorifico inferior do biogás) / 1.000.000.000) x 0,38 (Rendimento termoelétrico do motor) - (4.800,00 (Horas de safra no ano) $\times 200$ (Dias de safra no ano) $\times($ Eq A1/4.000)/1000))

Eq A31: Eq A30 x (US\$ 26,04, US\$ 52,08, US\$ 78,125, US\$ 104,16 e US\$ 130,20 (Preço do MWh))

Eq A32: ( (( (Eq A2 $\times 6$ (Volume de biogás produzido por $\mathrm{m}^{3}$ de vinhaça $\left.\left(\mathrm{N} \mathrm{m}^{3} / \mathrm{m}^{3}\right)\right) \times(1-0,05) \times 17.765,00$ (Poder calorifico inferior do biogás) / 1.000.000.000) x 0,38 (Rendimento termoelétrico do motor) x 89,29 (Fator de $\mathrm{NO}_{\mathrm{x}}$ evitado através da geração de eletricidade $(\mathrm{g} / \mathrm{MWh}))$ ) / 1000.000,00) 296 (Equivalente de $\mathrm{CO}_{2}$ para 1 ton de $\mathrm{NO}_{x}$ )

Eq A33: Eq A32 x US\$ 18,72 (Preço da tCO 2 eq)

Eq A34: Eq A31 + Eq A33 + US\$ 471,35

Eq A35: Eq A31 x 5,93\% (Impostos sobre venda, renda e contribuições sociais sobre a venda de eletricidade)

Eq A36: Eq A10 + Eq A12 + Eq A35

Eq A37: Eq A34 - Eq A36 